\title{
Comparative study of the methods for the determination of organic carbon and organic matter in soils, compost and sludge
}

\author{
V. R. Angelova ${ }^{1 *}$, V. I. Akova ${ }^{2}$, K. I. Ivanov ${ }^{1}$ \\ ${ }^{1}$ Department of Chemistry, Agricultural University-Plovdiv, 4000 Plovdiv, Bulgaria \\ ${ }^{2}$ Fruit Growing Institute-Plovdiv, 4004 Plovdiv, Bulgaria
}

Received July 4, 2018; Revised March 19, 2019

\begin{abstract}
The aim of this study was to compare the most commonly used methods for the determination of organic carbon (OC) and organic matter (SOM), and evaluate the capability of LOI (loss on ignition method) to estimate OC, using reference soils, compost and sludge as standards. The use of a titrimetric endpoint (adding phosphoric acid prior to titration) is more suitable for assessing the level of organic carbon in soils with low, medium, high and very high content. The use of a photometric endpoint is more appropriate for samples of medium and high carbon content. LOI 400 and LOI 450 may also be used for the determination of samples with a high organic content whereas LOI 450 - in the determination of samples with an average organic content. LOI 450 can be used to evaluate SOC in a wide range of organic matter concentrations (3-55\%). Indirect assessment of the organic carbon content or organic matter using a correction coefficient is not very accurate for samples with average organic carbon content.
\end{abstract}

Keywords: methods, organic carbon, organic matter, certified samples

\section{INTRODUCTION}

For the study of soil reactions and soil contamination, reliable knowledge of soil organic matter (SOM) or soil organic carbon (OC) is required [1-3]. Soil organic matter affects many soil properties including: (i) the soil's capacity to deliver $\mathrm{N}, \mathrm{P}$ and $\mathrm{S}$ and essential elements in plants; (ii) water infiltration and retention, (iii) degree of aggregation and general soil structure that influence air and water balance; (iv) cation exchange capacity; (v) soil colour; and (vi) adsorption or desorption of chemical pollutants.

Organic substances in the soil are generally classified as non-humus and humus [4], with humus substances being a major part of organic matter in most soils. There is a wide variety of methods for assessing the content and composition of humus. The main part of the methods used for quantification of humus is based on the determination of the amount of organic carbon as a predominant element in the composition of the soil organic matter. Carbon from soil samples is converted to carbon dioxide, which is measured directly or indirectly by different methods. Organic carbon can be measured by dry combustion at high temperatures in furnaces and $\mathrm{CO}_{2}$ determination with automatic analyzers [5] or by oxidation with acidic mixtures followed by titration of the dichromate residue with ferric ammonium sulfate or photometric determination of $\mathrm{Cr}^{3+}$ [6]. The dry combustion method is considered to be one of the most precise and accurate procedures, but the high

\footnotetext{
* To whom all correspondence should be sent: E-mail: vileriz@abv.bg
}

cost of the apparatus is a major limiting factor determining the use of the method in few laboratories [7].

Oxidation with a bichromic mixture (wet combustion) is widely used as a routine method by most laboratories due to the simplicity and speed of the method as compared to the dry combustion method [8]. Titrimetric and photometric methods can be used for the quantification of organic carbon in the samples [8]. In titrimetric methods, the residue of $\mathrm{Cr}_{2} \mathrm{O}_{7}^{2-}$ is titrated with $\mathrm{Fe}\left(\mathrm{NH}_{4}\right)_{2}\left(\mathrm{SO}_{4}\right)_{2} \cdot 6 \mathrm{H}_{2} \mathrm{O}$ (Mohr's salt), while in the spectrophotometric methods the green colour due to $\mathrm{Cr}^{3+}$ is quantitated at a wavelength of $660 \mathrm{~nm}$ after pre-calibration of the standard glucose method $[9,10]$.

In recent years, it has been increasingly preferred to use alternative methods such as the LOI (loss on ignition) method to wet combustion in order to eliminate the use and disposal of potassium bichromate containing $\mathrm{Cr}^{6+}$, which is carcinogenic and causes environmental pollution [7,11]. The use of the LOI method for the assessment of soil organic matter and SOC is recommended by many authors and criticized by others. The advantages of the method include the simultaneous analysis of a large number of samples and the low cost of equipment [7]. According to the procedure, soil samples are incinerated at high temperature in a muffle furnace where the organic matter is combusted. When determining the organic matter in soils by the LOI method, an incineration temperature of $400^{\circ} \mathrm{C}$ is recommended for $16 \mathrm{~h} \mathrm{[8]}$ or $450^{\circ} \mathrm{C}$ for $4 \mathrm{~h} \mathrm{[12].} \mathrm{A} \mathrm{combination} \mathrm{of} \mathrm{a} \mathrm{higher}$ 
$V$. R. Angelova et al.: Comparative study of the methods for the determination of organic carbon and organic matter ... temperature with a longer warm-up time may lead to an increase in the results obtained by this method [12]. This may be due to: (i) the removal of hygroscopic and intercrystalline $\mathrm{H}_{2} \mathrm{O}$ from clay minerals $[13,14]$, (ii) the loss of $\mathrm{H}_{2} \mathrm{O}$ from hydroxyl groups in the sesquioxides [13] and (iii) the charring of the elemental C [15].

Various methods are available in the literature to determine the OC in soil samples. Several studies have been dedicated to the comparison of a traditional wet chemical method using sets of soil samples, others use dry combustion at high temperatures followed by the detection of evolved $\mathrm{CO}_{2}$ or the SOC content is determined by weight loss on ignition [5,16,17]. Since all methods available have some limitations, the choice of assessment methodology is a critical decision for accurate quantification of SOC content.

The present study is an attempt to solve some of the discussion questions related to the quantification of organic carbon in soils, compost and sludge with low, medium and high content of organic matter using reference materials. Reference materials play a critical role in validating analytical methods and assessing accuracy and comparability of results among different laboratories.

The aim of the present paper was to compare the most commonly used methods for the determination of organic carbon (OC) and organic matter (SOM), evaluate the capability of LOI to estimate OC, as well as their comparability and compatibility, accuracy, precision, speed of determination and convenience, using reference soils, compost and sludge as standards.

\section{EXPERIMENTAL}

In the comparative study of the methods for determination of organic carbon, 7 certified soil samples and composts with total carbon content (\%) and organic matter content $(\%)$ were used as follows: standard 1 (soil) NCS DC $73386-0.32 \pm 0.13$ (OC) and $9.1 \pm 0.13(\mathrm{OM})$, standard 2 (soil) NCS DC $85106 \mathrm{a}-3.85 \pm 0.133(\mathrm{OM})$, standard 3 (chanel sludge) ISE $859-11.4 \pm 1.13(\mathrm{OC})$ and $21.7 \pm 1.0$ (OM), standard 4 (clay) ISE $952-1.66 \pm 0.204$ (OC) and $9.17 \pm 1.005(\mathrm{OM})$, standard 5 (organic ferrasol) ISE $998-1.66 \pm 0.204(\mathrm{OC})$ and $14.0 \pm 0.093(\mathrm{OM})$, standard 6 MARSE P205 (compost) - $42.4 \pm$ 0.85(OM) and standard 7 MARSE P206 (sewage sludge $)-54.4 \pm 0.76(\mathrm{OM})$. Organic carbon in the certified samples was determined according to ISO 14235 [10] (oxidation with bichromate and subsequent photometric and titrimetric determination) and the content of organic matter was determined directly by the LOI measurement method at $400^{\circ} \mathrm{C}$ and $450^{\circ} \mathrm{C}$ and indirectly by recalculating the organic carbon content, determined titrarily and photometrically by a correction coefficient.

For spectrophotometric determination, a spectrophotometer Pharo 100 (Merck KGaA) was used at a wavelength of $660 \mathrm{~nm}$ after preliminary calibration of the standard glucose method.

Titration was performed with an automatic burette with $0.2 \mathrm{~N} \mathrm{Fe}\left(\mathrm{NH}_{4}\right)_{2}\left(\mathrm{SO}_{4}\right)_{2} \cdot 6 \mathrm{H}_{2} \mathrm{O}$ and a phenylanthranilic acid indicator in two versions addition of $\mathrm{H}_{3} \mathrm{PO}_{4}$ prior to titration and titration without addition of $\mathrm{H}_{3} \mathrm{PO}_{4}$.

According to the LOI methods, the glass (without sample) was heated in a muffle furnace at $400^{\circ} \mathrm{C}$ for $2 \mathrm{~h}$, and after tempering, its weight was measured. To the tared glass $5 \mathrm{~g}$ of air-dry soil were added, heated at $105^{\circ} \mathrm{C}$ for $24 \mathrm{~h}$. After the tempering of the glass in the desiccator, the weight of the cup and the sample was measured. The glass with the sample was again placed in a muffle furnace at $400^{\circ} \mathrm{C}$ for $16 \mathrm{~h}$ (LOI 400) or $6 \mathrm{~h}$ at $450^{\circ} \mathrm{C}$ (LOI 450).

The loss in soil weight, expressed as a percentage of the dry soil weight, was calculated according to the following equations:

LOI $(\%)=($ Weight $105-$ Weight 400$) /$ Weight $105 \times 100$ LOI $(\%)=($ Weight105 - Weight 450$) /$ Weight $105 \times 100$

All definitions were made in three iterations. Comparison of the results obtained for organic carbon and organic matter by titrimetric methods, photometric methods and LOI was performed by regression analysis using the Windows SPSS program.

\section{RESULTS AND DISCUSSION}

The results obtained for the 7 certified standard samples determined according to ISO 14235 [10] (oxidation with bichromate and subsequent photometric and titrimetric determination) are presented in Table 1 and Fig. 1. From the results presented in Table 1 it is evident that there is no significant difference in the quantification of organic carbon with photometric and titrimetric endpoint. In most of the samples tested no significant differences were observed between the values obtained by both methods except for standard 1. Table 1 also presents the results for titrimetric determination of organic carbon with addition and without addition of phosphoric acid prior to titration. A full match of the photometric and titrimetric results is observed with the addition of phosphoric acid prior to titration. The addition of phosphoric acid helps to more accurately determine the equivalent point. The addition of $\mathrm{H}_{3} \mathrm{PO}_{4}$ to the digestive mix after the sample has cooled was used 
$V . R$. Angelova et al.: Comparative study of the methods for the determination of organic carbon and organic matter ... to help eliminate interferences from iron $\left(\mathrm{Fe}^{3+}\right)$ that may be present in the sample.

(sulfochromic oxidation) and the certified values in

Figure 1a shows the relationship between organic carbon determined by ISO 14235 [10]

Table. 1. Content of organic carbon in certified standard samples determined by oxidation with bichromate and subsequent photometric and titrimetric determination

\begin{tabular}{lccccccc}
\hline Standard & St.1 & St. & St.3 & St.4 & St.5 & St.6 & St.7 \\
\hline Certified values & $0.32 \pm 0.05$ & & $11.4 \pm 1.3$ & $2.13 \pm 0.29$ & $1.66 \pm 0.20$ & & \\
Photometric & $0.09 \pm 0.01$ & $2.12 \pm 0.30$ & $11.91 \pm 1.1$ & $2.27 \pm 0.30$ & $1.73 \pm 0.21$ & $23.18 \pm 1.3$ & $27.94 \pm 1.5$ \\
Titration & $0.27 \pm 0.05$ & $2.15 \pm 0.32$ & $11.02 \pm 1.2$ & $2.14 \pm 0.31$ & $1.72 \pm 0.20$ & $22.16 \pm 1.5$ & $25.74 \pm 1.5$ \\
Titration $+\mathrm{H}_{3} \mathrm{PO}_{4}$ & $0.30 \pm 0.05$ & $2.13 \pm 0.31$ & $11.47 \pm 1.1$ & $2.28 \pm 0.31$ & $1.78 \pm 0.22$ & $23.63 \pm 1.5$ & $28.0 \pm 1.5$ \\
\hline
\end{tabular}

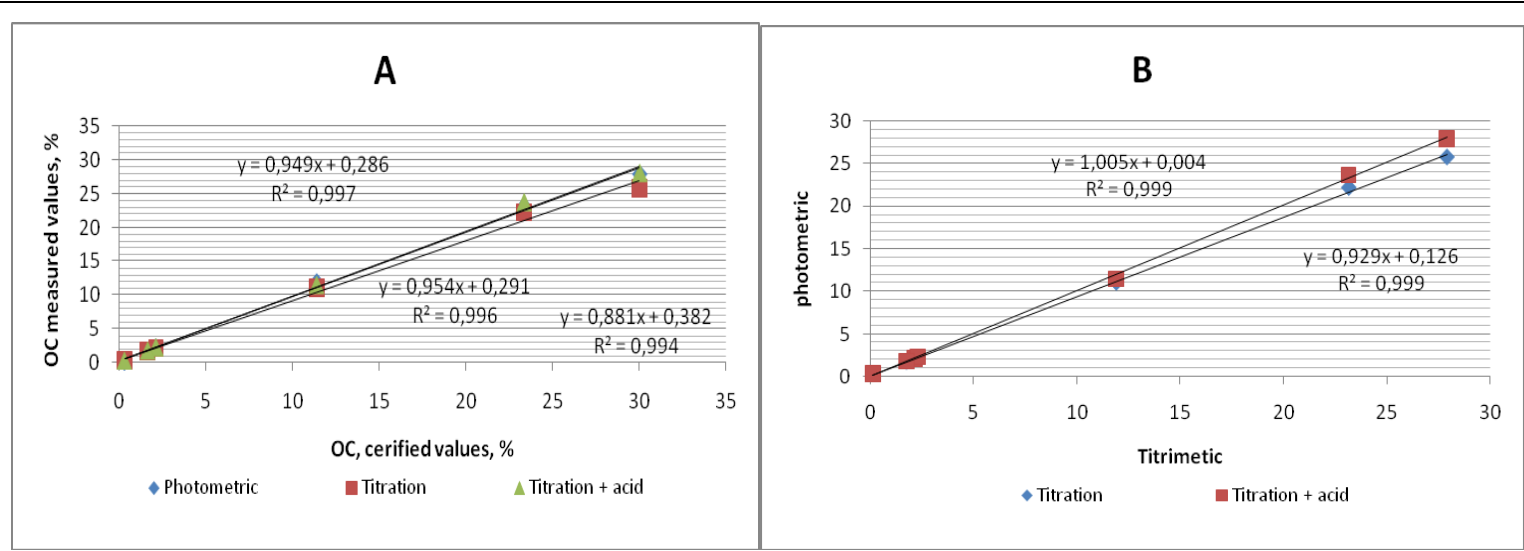

Figure 1. Linear regression analysis between organic carbon determined by sulfochromic oxidation and the certified values in samples (A) and organic carbon determined by photometric and titrimetric methods (B)

Table 2. Content of organic matter in the certified samples recalculated with a coefficient of 1.724

\begin{tabular}{lccccccc}
\hline Standard & St.1 & St.2 & St.3 & St.4 & St.5 & St.6 & St.7 \\
\hline Certified values & $9.1 \pm 0.5$ & $3.85 \pm 0.13$ & $21.71 \pm 1.0$ & $9.17 \pm 1.005$ & $14 \pm 0.93$ & $42.4 \pm 0.85$ & $54.4 \pm 0.74$ \\
Photometric & 0.16 & 3.6 & 20.52 & 3.92 & 2.98 & 40.0 & 48.2 \\
Titration & 0.47 & 3.71 & 18.99 & 3.69 & 2.97 & 38.2 & 44.4 \\
Titration $+\mathrm{H}_{3} \mathrm{PO}_{4}$ & 0.51 & 3.67 & 19.77 & 3.93 & 3.07 & 40.8 & 48.3 \\
\hline
\end{tabular}

Table 3. Content of organic matter in the certified samples recalculated by the equation: $\%$ organic matter = $0.35+(1.8 \times \%$ organic $\mathrm{C})$

\begin{tabular}{lccccccc}
\hline Standard & St.1 & St.2 & St.3 & St.4 & St.5 & St.6 & St.7 \\
\hline Certified values & $9.1 \pm 0.5$ & $3.85 \pm 0.13$ & $21.71 \pm 1.0$ & $9.17 \pm 1.005$ & $14 \pm 0.93$ & $42.4 \pm 0.85$ & $54.4 \pm 0.74$ \\
Photometric & 0.52 & 4.16 & 21.78 & 4.44 & 3.46 & 42.07 & 50.64 \\
Titration & 0.84 & 4.22 & 20.19 & 4.202 & 3.446 & 40.24 & 46.68 \\
Titration $+\mathrm{H}_{3} \mathrm{PO}_{4}$ & 0.89 & 4.18 & 21.0 & 4.454 & 3.55 & 42.97 & 50.75 \\
\hline
\end{tabular}

Figure $1 \mathrm{~b}$ shows the relationship between organic carbon determined photometrically and titrimetrically using linear regression analysis. As seen, there is a well-defined linear dependence $(\mathrm{R}=$ 0.999) between the amount of organic carbon determined titrimetrically and photometrically, using oxidation with bichromate according to ISO 14235 [10].

There are two approaches to assessing organic matter in soils. The first one is an indirect method based on the recalculation of the results of the organic carbon content in soils with correction coefficient, while the second one is the direct determination of the organic matter by the LOI method. Nelson and Sommers [8] propose to use the correction coefficient 1.724 as 344 a factor for converting organic carbon into an organic substance. According to Ranney [18], however, the organic matter content in the surface horizons can be sufficiently accurately calculated by the equation:

$\%$ organic matter $=0.35+(1.8 \times \%$ organic $\mathrm{C})$.

Tables 2 and 3 show the results obtained for the organic matter content of the certified samples recalculated on the basis of results obtained for organic $\mathrm{C}$ by the titrimetric and photometric methods.

As can be seen from Tables 2 and 3, the results for organic carbon obtained by sulfochromic oxidation using the ISO method with a photometric endpoint can be used for 
$V$. R. Angelova et al.: Comparative study of the methods for the determination of organic carbon and organic matter ... assessing the organic matter in cases of low and high organic carbon content in the samples. A very good match of the results between the calculated organic matter based on the organic carbon obtained by the titrimetric methods is observed for standards 2, 3, 6 and 7. However, in standards 1, 4 and 5 (with an average organic content) unsatisfactory results are obtained.

The results obtained for the seven certified standard samples by LOI 400 and LOI 450 are presented in Table 4.

Table 4. Content of organic matter in the certified samples by LOI 400 and LOI 450

\begin{tabular}{lccccccc}
\hline Standard & St.1 & St.2 & St.3 & St.4 & St.5 & St.6 & St.7 \\
\hline Certified values & $9.1 \pm 0.5$ & $3.85 \pm 0.13$ & $21.71 \pm 1.0$ & $9.17 \pm 1.005$ & $14 \pm 0.93$ & $42.4 \pm 0.85$ & $54.4 \pm 0.74$ \\
LOI 400 & $3.76 \pm 0.5$ & $5.92 \pm 0.20$ & $20.72 \pm 1.1$ & $6.65 \pm 0.85$ & $7.58 \pm 0.56$ & $42.80 \pm 0.90$ & $53.14 \pm 0.80$ \\
LOI 450 & $6.33 \pm 0.5$ & $6.34 \pm 0.20$ & $21.08 \pm 1.2$ & $9.03 \pm 0.95$ & $13.66 \pm 0.99$ & $41.85 \pm 0.90$ & $53.39 \pm 0.85$ \\
\hline
\end{tabular}

There is a good match of results for both LOI 400 and LOI 450 in standard 3 (chanel sludge), 6 (compost) and 7 (sewage sludge), i.e. in samples with a high organic matter content. For these samples, the organic matter content determined at $400^{\circ} \mathrm{C}$ for $16 \mathrm{~h}$ is identical to that determined at $450^{\circ} \mathrm{C}$ for $6 \mathrm{~h}$. The results presented in Table 4 show that the duration and temperature of the sample heating have influence. Increased temperature and shorter heating of samples with low and medium organic matter content lead to more accurate results corresponding to the certified values. For standards 1, 4 and 5, the organic matter content determined at $400^{\circ} \mathrm{C}$ is significantly lower than at $450^{\circ} \mathrm{C}$, suggesting that the incomplete combustion of organic matter at this lower temperature and longer heating time cannot compensate for the low $\left(400^{\circ} \mathrm{C}\right)$ incineration temperature. Apparently the sample processing time is not sufficient and should be increased (up to $24 \mathrm{~h}$ and more) to obtain correct results for standard samples 1,4 and 5 .

The temperature at which LOI is determined is important, as this method not only measures organic matter, but also the $\mathrm{CO}_{2}$ losses from carbonates and the loss of structural water from clay minerals. Studies of Ball [15] and Ben-Dor and Banin [19] show that dehydroxylation of phyllosilicates occurs at temperatures below $450^{\circ} \mathrm{C}$. Gibbsite is an exception, as it is reported that this clay mineral loses structural water when heated at 300 to $350^{\circ} \mathrm{C}$ [18]. This process depends not only on the amount of clay but also on its mineralogical nature. Standard sample 4 is clay, and 5 is organic ferrasol. It is known that organic ferrasol is predominant in kaolinite and has a high content of sesquioxides. A problem with the LOI method is that some clay minerals may lose structural water (i.e, water that is part of the matrix) or hydroxyl groups at temperatures $\left(400-450^{\circ} \mathrm{C}\right)$ used in the incineration of samples.

The loss of structural water will increase the total weight loss of the sample, which will result in higher results for the organic matter content of the samples. These weight losses can have a significant impact for soils containing little organic matter and high clay content. At a low organic content, the dehydroxylating of clays is much more likely and the loss of weight from the dehydroxylating of the clay may be greater.

Figure 2 shows the relationship between the organic matter determined by LOI 400 and LOI 450 and the certified values in the samples using a linear regression analysis.

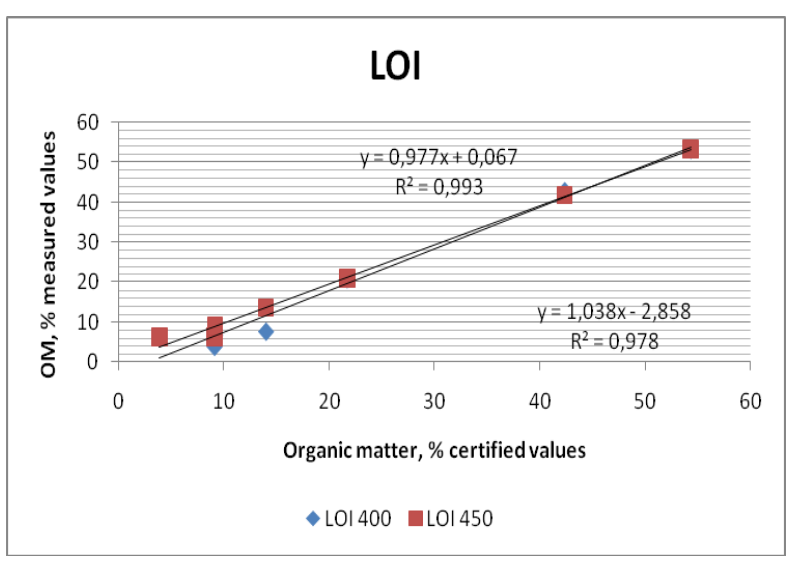

Fig. 2. Linear regression analysis between the organic matter determined by LOI 400 and LOI 450 and the certified values in the samples.

As can be seen from Fig. 2, there is a linear relationship between the amount of soil organic matter (SOM) determined by the LOI method and its content in the certified samples. The $\mathrm{R}^{2}$ regression coefficient is 0.997 for LOI 450 and 0.991 for LOI 400. The values of the "b" regression coefficient below 1 suggest that some components other than organic matter are lost during heating while the coefficients greater than 1 indicate that an incomplete removal of organic matter has occurred $[19,20]$. The results we obtained show that the coefficient is higher than $1(5.073)$ at the lower temperature $\left(400^{\circ} \mathrm{C}\right)$, while at the higher temperature $\left(450^{\circ} \mathrm{C}\right)$ the coefficient is close to 1 (1.094).

Most authors use regression analysis to 
$V$. R. Angelova et al.: Comparative study of the methods for the determination of organic carbon and organic matter ... describe the relationship between OC and OM through LOI. The idea of using a factor that can turn LOI into organic $\mathrm{C}$ is attractive because OM can easily be determined by LOI, unlike organic C.

The results obtained for an organic substance by the LOI method were compared with the data for organic carbon, obtained by the titrimetric methods and photometric method (Fig. 3). A very good correlation between LOI 400 and LOI 450 with $\mathrm{OC}$ is found. The comparison of the organic substance obtained by oxidation with potassium dichromate with a titrimetric and photometric endpoint and LOI 400 and LOI 450 in a wide range of the organic matter concentration (approximately $3-55 \%$ ) shows a correlation coefficient of 0.99 .

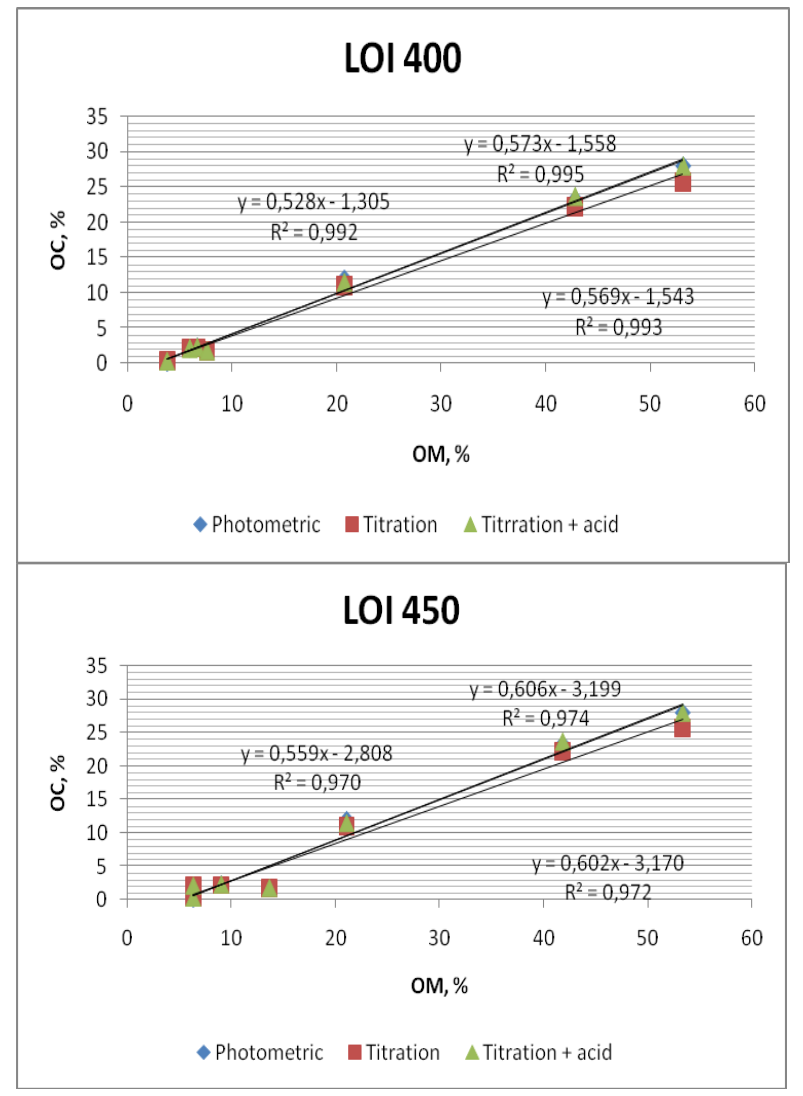

Fig. 3. Linear regression analysis between the organic matter determined by the LOI method and organic carbon, obtained by the titrimetric methods and the photometric method.

The results obtained show that LOI can be used to evaluate SOC in samples with low, medium and high organic carbon contents.

\section{CONCLUSIONS}

The most important criteria for choosing a method for determining organic carbon and organic matter in soils, composts and sludge are the reagent consumption, the duration of the analysis, the accuracy of measurement and the reproducibility of the results. Considering these criteria, we can recommend the use of sulfochromic oxidation by ISO to determine organic carbon in the samples. The use of the titrimetric endpoint (adding phosphoric acid prior to titration) is more suitable for assessing the level of organic carbon in soils with low, medium, high and very high content. The use of a photometric endpoint is more appropriate for samples of medium and high carbon content.

LOI analyses have advantages primarily related to the ability to simultaneously determine a large number of samples. LOI 400 and LOI 450 may also be used for the determination of samples with a high organic content. We recommend the use of LOI 450 in the determination of samples with an average organic content.

LOI 450 can be used to evaluate SOC in a wide range of organic matter concentrations (3$55 \%)$.

Acknowledgement: The financial support by the Bulgarian National Science Fund Project DFNI H04/9 is greatly appreciated.

\section{REFERENCES}

1. J.-I. Drever, The geochemistry of natural waters, surface and groundwater environments, Prentice Hall, Upper Saddle River, New York, 1997.

2. J.-G. Smith, Geograf. Annal., Series A: Phys. Geogr., 85, 91 (2003).

3. N.-C. Brady, R. Weil, Nature and properties of soils, Prentice Hall, Upper Saddle River, New York, 2007.

4. M. Klavins, Aquatic Humic Substances: Characterisation, Structure and Genesis, University of Latvia, Riga, 1997.

5. B. Schumacher, Methods for the determination of total organic carbon in soils and sediments, NCEAC-1282, EMASC- 001, 1, 2002.

6. R.-H. Ellerbrock, H.-H. Gerke, J. Bachmann, M.-O. Goebel, Soil Sci. Soc. Am. J., 69, 57 (2005).

7. M.-E. Konen, P.-M. Jacobs, C.-L. Burras, B.-J. Talaga, J.-A. Mason, Soil Sci. Soc. Am. J., 66, 1878 (2002).

8. D. -W. Nelson, L.-E. Sommers, Proc. Indiana Acad. Sci., 84, 456 (1975).

9. D.-L. Heanes, Commun. Soil Sci. Plant Anal., 15, 1191 (1984).

10. ISO 14235 , Soil quality. Determination of organic carbon by sulfochromic oxidation, 1988.

11. E. E. Schulte, A. Kaufmann, J. B. Peter, Commun. Soil Sci. Plant Anal., 22, 159 (1991).

12. C.-A. Cambardella, A.-M. Gajda, J.-W. Doran, B.-J. Wienhold, T.-A. Kettler, in: Assessment methods for soil carbon, R. Lal et al. (eds.), Lewis Publ., New York, 2001, p. 349. 
$V . R$. Angelova et al.: Comparative study of the methods for the determination of organic carbon and organic matter ...

13. A. Goldin, Commun. Soil Sci. Plant Anal., 18, 1111 (1987).

14. M.-B. David, Commun. Soil Sci. Plant Anal., 19,1593 (1988).

15. D.-F. Ball, J. Soil Sci., 15, 84 (1964).

16. S. Sleutel, S. De Neve, B. Singier, G. Hofman, Communications in Soil Science and Plant Analysis, 38, 2647 (2007).
17. H. Spiegel, E. Filcheva, P. Hegymegi, A. Gal, F. Verheijen, Soil Sci. Agrochem. Ecol., 4, 3 (2007).

18. R.-W. Ranney, Soil Sci. Soc. Am. Proc., 33, 809 (1969).

19. E. Ben-Dor, A. Banin, Commun. Soil Sci. Plant Anal., 20, 1675 (1989).

20. T. T. Gorsuch, The destruction of organic matter, Oxford, New York, Pergamon Press, 1970. 